\title{
Size Selection of Mussels by the Blue Crab Callinectes sapidus: Energy Maximizer or Time Minimizer?
}

\author{
R. N. Hughes and R. Seed \\ Department of Zoology, University College of North Wales, Bangor, Gwynedd, Wales, U. K.
}

\begin{abstract}
Blue crabs Callinectes sapidus Rathbun fed rapaciously on mussels Geukensia (= Modiolus) demissa (Dillwyn) in the laboratory. Very small mussels were crushed immediately, slightly larger ones more slowly across the umbonal region; all larger mussels were opened by gradually chipping the posterior edges of the shell, severing the posterior adductor and tearing the valves apart. Handling time increased with mussel volume, while profitability (yield of flesh per unit handling time) decreased monotonically as mussel size increased. C. sapidus preferred smaller to larger mussels, thereby simultaneously minimizing the time spent handling prey and maximizing the net rate of energy intake. The relative importance of 'energy maximization' and 'time minimization' could not be distinguished. C. sapidus could reduce the recognition procedure for optimal (smaller) mussels from several seconds of manipulation by the mouthparts and chelae to an instantaneous touch by a walking leg after a few minutes experience. The physico-chemical basis of prey evaluation by $C$. sapidus remains to be determined.
\end{abstract}

\section{INTRODUCTION}

Elner and Hughes (1978) showed that shore crabs Carcinus maenas (L.) feeding on Mytilus edulis L. in the laboratory, appear to conform to the predictions of Optimal Diet Theory based on the energy maximization premise (reviewed by Krebs, 1978; Hughes, 1980). The ability to evaluate prey and to choose a diet according to encounter rates with prey items of different values would seem to require a neurological mechanism of considerable sophistication. Although strongly suggesting an 'optimal foraging' behaviour in C. maenas, Elner and Hughes' data do not exclude the possibility of other underlying mechanisms that would coincidentally lead to an 'optimal diet'. We were therefore interested to see if another portunid crab, Callinectes sapidus, with rather different chelal morphology, would also adopt an apparently energy maximizing foraging behaviour when feeding on local mussels Geukensia (= Modiolus) demissa.

Callinectes sapidus occurs abundantly along the eastern seaboard of $N$. America and is known to eat a wide variety of items from detritus, plant material, benthic invertebrates, to fish (Darnell, 1961). Although C. sapidus is an opportunistic feeder, individuals may concentrate on certain abundant prey, for which special foraging techniques are used. Hamilton (1976) thus observed $C$. sapidus reaching out of the water to pick marsh periwinkles Littorina irrorata (Say) from the stems of cordgrass Spartina alterniflora. We observed $C$. sapidus emerge from saltmarsh creeks to catch fiddler crabs Uca spp.; these were dragged back to the water and dismembered, a feeding behaviour also recorded by Herrnkind (1968). Small to medium sized C. sapidus in the Newport River estuary at Beaufort, N. Carolina (USA), appear to specialise on Geukensia demissa (Seed, 1980a; present study). The crabs follow the flood tide onto the oyster-mussel zone on the local sea-walls, where they feed until the tide recedes. Experiments were designed to ascertain whether $C$. sapidus selects certain sized mussels and whether chosen mussels are those most profitable in terms of the yield of flesh per unit handling time.

\section{GENERAL METHODS}

Small to medium sized blue crabs which follow the incoming tide to forage in the intertidal zone were collected either by hand net or by baited lines from 
around Piver's Island in the immediate vicinity of Duke University Marine Laboratory (USA). Collections were made at approximately high water between late June and mid August, 1980. Crabs so obtained varied between about $5-12 \mathrm{~cm}$ in carapace width and were therefore considerably smaller than those which could be caught by trawling in the adjacent Sounds. Each crab was sized according to its carapace width (i. e. the maximum distance between the 2 prominent lateral spines) and the maximum cross sectional dimension of the major chela ( $=$ claw height) noted. Crabs were kept individually in plastic aquaria $(48 \mathrm{~cm} \times 33 \mathrm{~cm}$ ) filled to a depth of $15 \mathrm{~cm}$ with running seawater at $29^{\circ} \mathrm{C} \pm 1 \mathrm{C}^{\circ}$. It proved necessary to reduce visual disturbance of the crabs during experiments and this was achieved by fitting the aquaria with lids of $2 \mathrm{~cm}$ mesh plastic netting. Only male crabs were used in our fecding cxperiments in order to avoid potential bias that might otherwise be introduced through minor sexual differences in chelal morphology or predatory behaviour. Hunger levels were standardized by starving freshly caught crabs for $24 \mathrm{~h}$ before each experiment. Sediment, faecal material and shell debris were removed from the aquaria several times each day

All the mussels used in the feeding experiments were collected from a relatively restricted area within the prominent intertidal oyster zone along the local sea wall. This was done in order to minimize any variation in the shell characteristics which might exist between different Geukensia demissa populations. Sea-wall $G$. demissa, for example, are known to differ in their overall shell proportions from conspecifics situated in neighbouring salt marsh muds (Seed, 1980b). Care was also taken to exclude from our samples any Brachidontes exustus (L.), a small mytilid mussel which co-occurs with $G$. demissa on sea-walls and wharf pilings in this locality. Immediately after collection, the mussels were hand sorted and any fouling organisms removed from the shells. The length of each mussel was then measured to the nearest $0.1 \mathrm{~cm}$. Only freshly collected, undamaged mussels in apparently good condition were used as prey.

\section{EXPERIMENTS AND RESULTS}

\section{Prey Handling Techniques}

Feeding behaviour was generally prefaced by a period of active swimming and vigorous movements of the mouthparts. Mussels were apparently detected at a distance of several $\mathrm{cm}$ through the water, presumably by chemoreceptors on the antennae, whilst any mussel touched by the walking legs elicited an immediate response from a hungry crab. The fringes of hairs on the inner edges of the walking legs are especially sensitive and once these come into contact with a suitable item of prey it is drawn forward under the body towards the mouth. When feeding on mussels the prey is manipulated not only by the chelae but also by the anterior walking legs and the large outer pair of maxillipeds (Fig. 1,1). Small mussels are easily crushed outright. These are held by one chela whilst force is applied to the shell by the other chela. Once the shell has been crushed, flesh is torn out by the claws and mouthparts and ingested. Attacks on somewhat larger mussels are centred on the weaker umbonal region. Following each unsuccessful attempt to crush the shell the position of the mussel is adjusted slightly until a weak spot is located and the umbones smashed (Fig. 1, $1 \& 2$ ). If the shell could not be opened after several crushing attempts it was frequently abandoned for another mussel. Larger mussels could not generally be crushed and an alternative, much slower, method of attack was employed. Here the posterior edges of the shells were gradually chipped (Fig. 1, 3 \& 4) until the chelae could eventually be forced between the valves, so tearing the posterior adductor muscle (Fig. 1, $5 \& 6$ ). The valves were then grasped by the chelae and pulled open in order to expose the flesh (Fig. 1, $7 \& 8$ ). When alternative prey was unavailable certain crabs would spend 3 h or more manipulating large mussels before these were eventually opened. Mussel shells attacked in this fashion often had a rather ragged appearance but otherwise remained largely intact.

\section{Prey Handling Times and Profitabilities}

Individual crabs were fed on mussels over a wide size range in order to determine the relationship between prey profitability and mussel size. Each mussel was gently lowered into the tank and the following events carefully timed:

(a) Opening time: The time from the crab's first physical contact with the prey item, through the period of manipulation to the point where the shell was finally opened and the first bite of exposed flesh taken.

(b) Eating time: The period from when the mussel was opened to the point where the meal was completed and the empty shell abandoned. Opening time also includes the time spent re-manipulating and re-breaking parts of the shell so as to extract the full complement of food.

(c) Handling time: The summation of Opening time and Eating time

The flesh of mussels over the size range used in the feeding experiments $(0.5-5.5 \mathrm{~cm})$ was dried to constant weight at $60^{\circ} \mathrm{C}$ and a regression of dry flesh weight on 
shell length calculated. Prey profitability is defined as dry flesh weight of mussel (mg)/handling time (min)

Variations in handling times of similarly sized mussels existed within and between crabs. The withincrab variation was probably mainly due to the variability of prey condition and shell strength, although slight differences in crab hunger levels could also have been involved. The between-crab variation was largely attributable to crab size, but certain crabs were more proficient at opening mussels than others, perhaps because of more experience with mussel prey hefore capture. Crab size was directly related to chelal
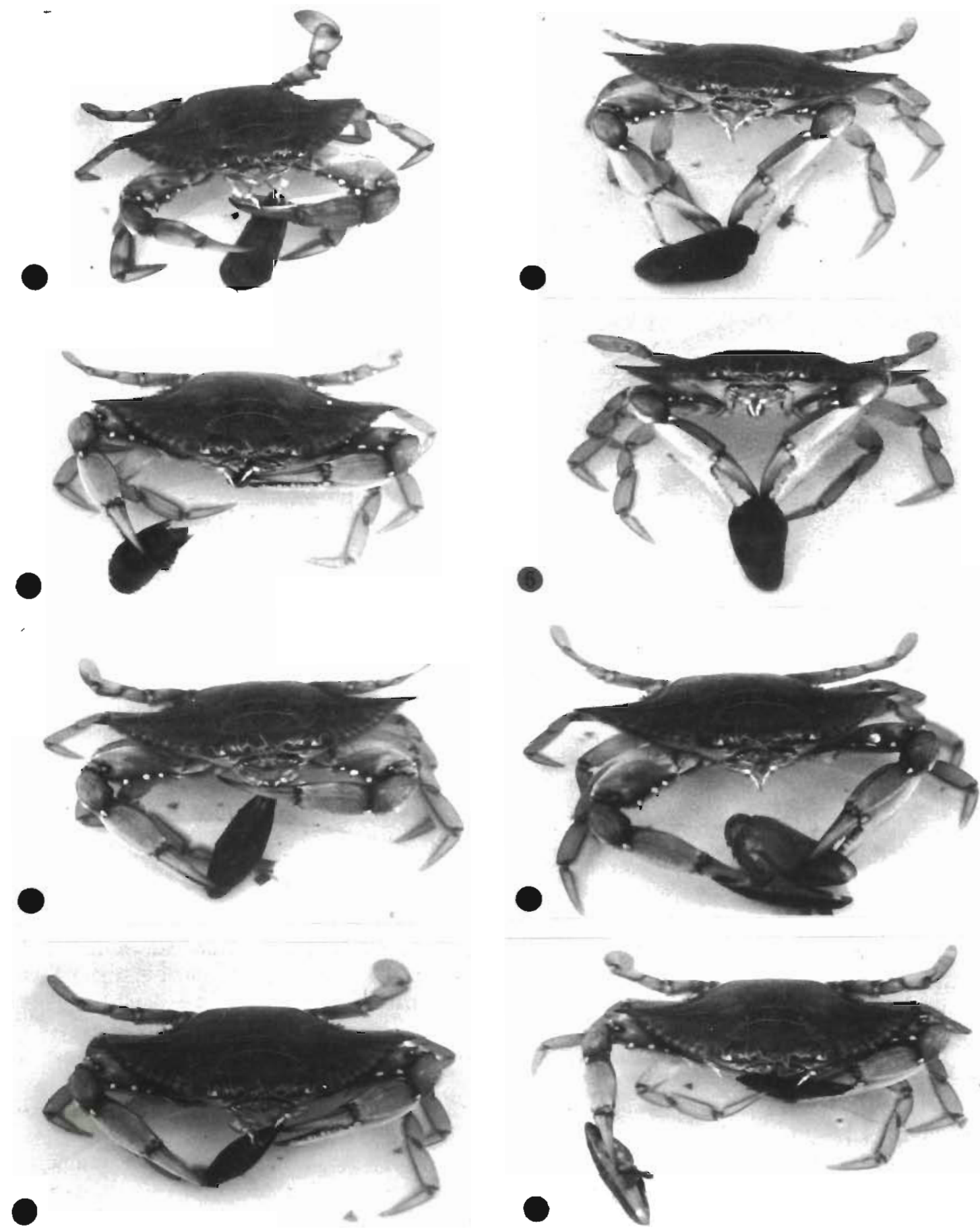

Fig. 1 Callinectes sapidus. Handling techniques used to open Geukensia demissa. See text for details 


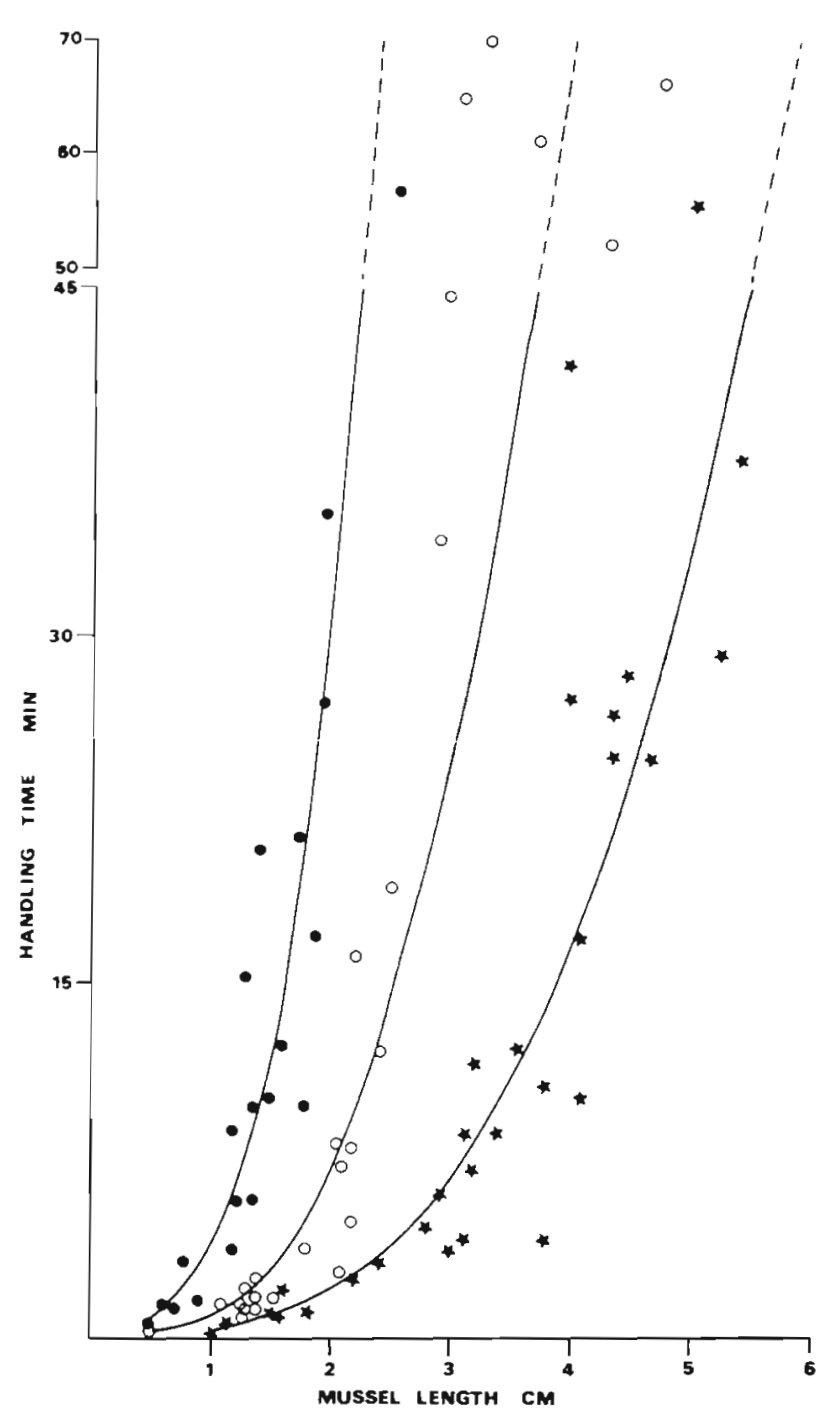

Fig. 2. Callinectes sapidus. Mussel handling time $\left(\mathrm{T}_{\mathrm{h}}\right)$ plotted against mussel length ( $L$ ) for 3 individual crabs. Curves fitted by power function $T_{\mathrm{h}}=\mathrm{aL}^{3.15} \bullet 5.2 \mathrm{~cm} \mathrm{crab}, \mathrm{a}: 1.20, \mathrm{n}: 20$; $8.5 \mathrm{~cm}$ crab, a: $-0.33, \mathrm{n}: 26 ; * 11.7 \mathrm{~cm}$ crab, a: $-1.59, \mathrm{n}: 30$ Curves selected to reflect the size range of crabs used in feeding experiments. Note different scale in upper portion of figure

strength, as indicated by the isometric relationship between carapace width and claw height:

$\log _{e}$ claw height $(\mathrm{cm})=1.02 \log _{e}$ carapace width $(\mathrm{cm})$ $-1.90 ; r^{2}=0.91 ; n=51$; range of carapace widths $=$ $5.2-17.5 \mathrm{~cm}$.

For a given crab, handling time increased quasiexponentially with prey length (Fig. 2). Power functions (logarithmic transformation of both variables) and exponential functions (logarithmic transformation of dependent variable) gave about equally good fits to the data. Analysis of covariance of regressions on loglog transformed data revealed a barely significant dif- ference among slopes for different crabs, $F_{135}^{7}=2.16$, $\mathrm{P} \geqslant 0.05$, but a highly significant difference among elevations, $F_{135}^{7}=38.2, P<0.001$. Larger, therefore stronger, crabs had lower elevations, reflecting their shorter handling times for a given sized mussel. The pooled sums of squares and cross-products between crabs gave a common slope of $3.15 \pm 0.11,(n=8)$ suggesting that handling time is a simple function of mussel volume (cube of shell length). Intercepts were recalculated for each crab using the common slope and the resulting equations were used in the calculation of prey profitabilities. Dry flesh weight of Geukensia demissa was related to shell length according to the regression:

$\log _{e}$ weight $(\mathrm{mg})=2.47 \log _{\mathrm{e}}$ shell length $(\mathrm{cm})+1.99$; $\mathrm{r}^{2}=0.99 ; \mathrm{n}=50$.

Prey profitability decreased monotonically from the smallest to the largest mussels (Fig. 3).

\section{Foraging Behaviour}

Individual crabs were presented with several size classes of mussels, each represented by 5 individuals scattered haphazardly over the floor of the aquarium. Crabs were allowed to feed for 2-3 h and the numbers of mussels eaten in each size category were then determined. Mussels were replaced after each feeding bout by ones of similar size to maintain constant prey availability. These experiments were repeated until a constant feeding pattern emerged (Fig. 3), by which time certain crabs had eaten 200-300 mussels. The largest mussels were seldom taken even though these could eventually be opened by all but the smallest crabs. A surprising, but consistent feature was the apparent reluctance of the crabs to eat the smallest, most profitable mussels. This could have been due to the smaller size classes being obscured amongst the larger mussels and broken shell debris. To test this possibility, two size classes of mussels, $2-2.5 \mathrm{~cm}$ and $3.5-4 \mathrm{~cm}$, representing more profitable and less profitable prey respectively, were fed in different proportions $(5: 5 ; 5: 10 ; 5: 20)$ to each of 4 crabs. Each crab was observed continuously for about $1 \mathrm{~h}$, noting handling times and acceptance-rejection sequences. Mussels were replaced as eaten to maintain constant prey availability, care being taken not to disturb the crab. Although the larger mussels were encountered much more frequently than expected from the proportions offered, they were rarely eaten (Table 1,1). The recorded encounter rates with larger mussels were less than the true values because crabs often skated over several larger mussels at a time, making it impossible to record individual encounters. Smaller mussels were 


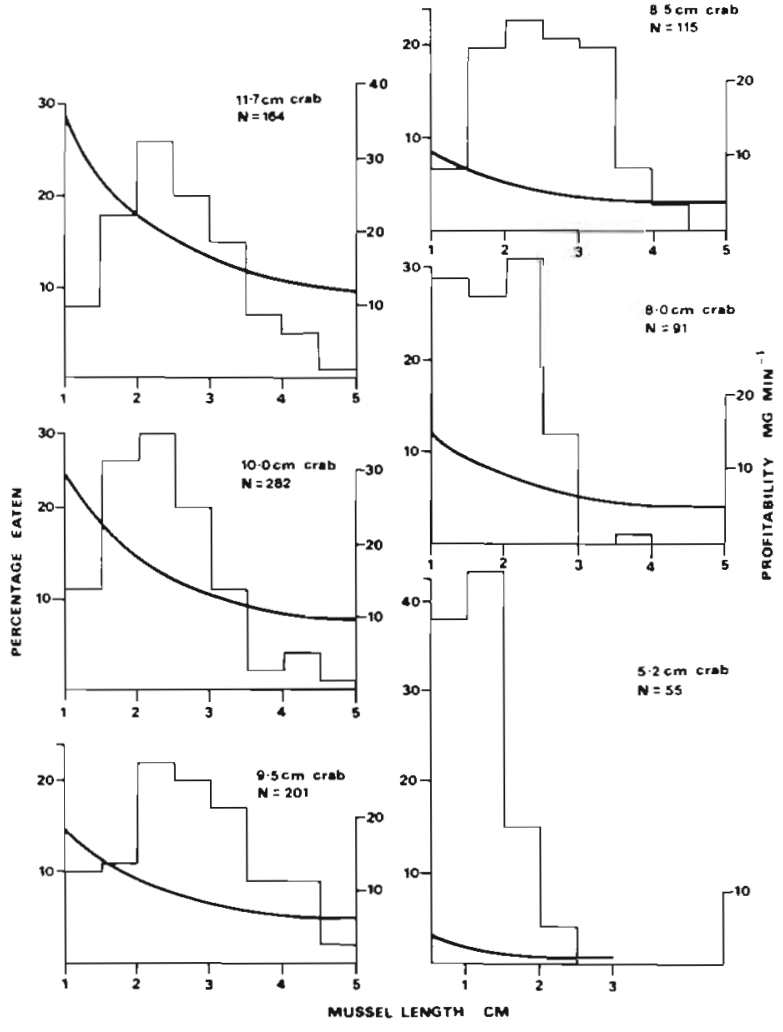

Fig. 3. Callinectes sapidus. Consumption of mussels of different size under conditions of constant prey availability. $\mathrm{N}$ : total number of mussels eaten during each experiment.

Curves denote profitability of mussels of different length

almost always eaten when encountered, even when grossly outnumbered by larger mussels (Table 1, 1).

A similar series of experiments, with the same crabs, was run using mixtures of $1-1.5 \mathrm{~cm}$ and $2-2.5 \mathrm{~cm}$ mussels. Mussels in both size categories could easily be opened and were rarely rejected (Table 1,2). Occa- sionally, however, small mussels were dropped and lost among the shell debris. The results in Table 1, 1 \& 2 confirm that the apparent reluctance to eat small mussels (Fig. 2) was simply due to low encounter rates with these prey.

Further experiments, using new crabs in addition to those used for the previous experiments, showed the same preference for smaller mussels, but there was greater within- and between-crab variability in the acceptance of larger mussels (Table 2, 1 \& 2). In certain trials, a crab would feed more readily than usual on larger mussels, but the handling times for these prey tended to be less than predicted. Evidently, these larger mussels were more easily opened than normal, perhaps due to injury when collected. As a result, the difference in average profitability between smaller and larger mussels presented was less than expected. The preference for smaller mussels was, nevertheless, consistently retained.

We conclude that Callinectes sapidus prefers smaller mussels to larger ones, but that the crab is somehow able to detect the increased vulnerability of weakened mussels, which may be attacked more readily than is normal for their size.

\section{DISCUSSION}

The series of methods used by Callinectes sapidus to open progressively larger Geukensia demissa is rather similar to that used by Carcinus maenas to open progressively larger Mytilus edulis (Elner, 1978). C. sapidus, however, seems always to adopt the posterioredge-chipping method to open larger mussels, whereas $C$. maenas also uses alternative methods (Elner, 1978). The effectiveness of the posterior-edgechipping method (Fig. 1, 3 \& 6), its complexity and

Table 1 Callinectes sapidus. Diets of crabs presented with different ratios of smaller:larger mussels $S_{a}$ : number of smaller mussels accepted, $L_{d}$ : number of larger mussels accepted, PS. proportion of smaller mussels in diet, $S_{e}$ : number of smaller mussels encountered (number accepted plus number rejected), $L_{F}$ : number of larger mussels encountered, PS $S_{k}$ : proportion of encountered mussels that were of the smaller size. $\chi^{2}$ is for departure of diet from random expectation based on encounter ratios

The same 4 crabs $(8.5-11.7 \mathrm{~cm})$ were used with each ratio

\begin{tabular}{|c|c|c|c|c|c|c|c|c|c|}
\hline \multirow[t]{2}{*}{ (1) } & \multicolumn{9}{|c|}{ Smaller mussels $=2-2.5 \mathrm{~cm}_{i}$ larger mussels $=3.5-4 \mathrm{~cm}$} \\
\hline & Ratio & $\mathrm{S}_{\mathrm{c}}$ & $\mathrm{L}_{\mathrm{s}}$ & $\mathrm{PS}_{\mathrm{d}}$ & $\mathrm{S}_{\mathrm{s}}$ & $\mathrm{L}_{*}$ & $\mathrm{PS}_{\mathrm{e}}$ & $x^{2}$ & $\mathrm{P}$ \\
\hline & $5: 5$ & 33 & 3 & 0.92 & 36 & 55 & 0.40 & 41.2 & $<0.001$ \\
\hline & $5: 10$ & 37 & 1 & 0.97 & 48 & 101 & 0.32 & 73.7 & $<0.001$ \\
\hline & $5: 20$ & 31 & 9 & 0.78 & 33 & 159 & 0.17 & 102.3 & $<0.001$ \\
\hline \multirow[t]{5}{*}{ (2) } & \multicolumn{9}{|c|}{ Smaller mussels $=1-1.5 \mathrm{~cm}$; larger mussels $=2-2.5 \mathrm{~cm}$} \\
\hline & Ratio & $S_{d}$ & $\mathrm{~L}_{\mathrm{c}}$ & $\mathrm{PS}_{\mathrm{a}}$ & $S_{e}$ & $L_{e}$ & $\mathrm{PS}_{\mathrm{e}}$ & $x^{2}$ & $\mathrm{P}$ \\
\hline & $5: 5$ & 19 & 40 & 0.32 & 21 & 41 & 0.34 & 0.08 & $>0.05$ \\
\hline & $10: 5$ & 33 & 40 & 0.45 & 33 & 40 & 0.45 & 0.00 & $>0.05$ \\
\hline & $20: 5$ & 81 & 40 & 0.67 & 81 & 43 & 0.65 & 0.15 & $>0.05$ \\
\hline
\end{tabular}


Table 2. Callinectes sapidus. Diets of crabs presented with different ratios of smaller:larger mussels. Notation as 1 n Table 1 1-3 crabs were used for each ratio and the total number of trials are given. $\infty$ denotes sequences of rapid, uncountable encounters with larger mussels. Size range of crabs used $5.2-11.7 \mathrm{~cm}$

\begin{tabular}{|c|c|c|c|c|c|c|c|c|c|}
\hline \multicolumn{10}{|c|}{ (1) Smaller mussels $2-2.5 \mathrm{~cm}$; larger mussels $3.5-4 \mathrm{~cm}$} \\
\hline Ratio & $S_{i}$ & $\mathrm{~L}_{t j}$ & $\mathrm{PS}_{\text {, }}$ & $S_{1}$ & $\mathrm{~L}_{1}$ & PS, & $x^{2}$ & $\mathrm{P}$ & Truals \\
\hline $5: 5$ & 34 & 8 & 0.81 & 41 & 68 & 0.38 & 33.6 & $<0.001$ & 4 \\
\hline $5 \cdot 10$ & 48 & 11 & 0.81 & 60 & 134 & 0.31 & 70.2 & $<0.001$ & 7 \\
\hline $5: 20$ & 24 & 9 & 0.73 & 29 & 132 & 0.18 & 66.9 & $<0.001$ & 4 \\
\hline $10: 10$ & 20 & 17 & 0.54 & 23 & 45 & 0.34 & 6.8 & $<0.01$ & 4 \\
\hline $10: 20$ & 2 & 4 & 0.33 & 3 & 8 & 0.27 & - & - & 1 \\
\hline $10: 20$ & 9 & 5 & 0.64 & 9 & $x$ & - & - & -- & 1 \\
\hline \multicolumn{10}{|c|}{ (2) Smaller mussels $1.5-2 \mathrm{~cm}$; larger mussels $3.5-4 \mathrm{~cm}$} \\
\hline Ratio & $\mathrm{S}_{4}$ & $L_{d}$ & $\mathrm{PS}_{\mathrm{d}}$ & $S_{c_{1}}$ & $\mathrm{~L}_{1}$ & $P S_{0}$ & $x^{2}$ & $\mathrm{P}$ & Trials \\
\hline $5: 5$ & 12 & 3 & 0.80 & 12 & 27 & 0.31 & 17.1 & $<0.001$ & 2 \\
\hline $10: 10$ & 6 & 8 & 0.43 & 6 & 29 & 0.17 & 6.5 & $<0.05$ & 4 \\
\hline $10: 5$ & 53 & 14 & 0.79 & 58 & 84 & 0.41 & 48.0 & $<0.001$ & 4 \\
\hline
\end{tabular}

similarjty in all the C. sapidus investigated, suggest that it is a specific handling technique for mussels. Whether this technique is learned or innate remains unknown.

The monotonically decreasing profitability curves for Callinectes sapidus feeding on Geukensia demissa contrast with the peaked profitability curves for Car cinus meanas feeding on Mytilus edulis (Elner and Hughes, 1978). A probable explanation is that the chelae of $C$. sapidus have slenderly tapered dactyls enabling the shells of even the smallest mussels to be gleaned efficiently, whereas the chelae of $C$. maenas have blunter dactyls that are less efficient at gleaning very small mussels.

Because Optimal Diet Theory predicts that less profitable prey should be eaten according to their relative abundance whenever the time taken to evaluate prey, or the probability of incorrect evaluation, become significant (Hughes, 1979), it is not possible to falsify the theory by examining diet selection alone. The problem becomes one of distinguishing between active diet selection and passive selection resulting from mechanical properties of the predator and prey. Do crabs evaluate mussels by measuring some aspect of size and vulnerability, or do they merely adopt a certain persistence time' that is perhaps a function of hunger level? Carcinus maenas seems to show an active choice among Mytilus edulis but a passive choice among the dogwhelk Nucella lapillus (L.) (Hughes and Elner, 1979). Both types of behaviour, whether through natural selection or by coincidence, maximize the net rate of energy intake by C. maenas.

The evidence is strongly in favour of an active choice of mussel sizes by Callinectes sapidus. Immediate acceptances of smaller mussels and repeated rejections of larger ones constituted the basic behavioural patterns of feeding crabs. However, since profitability increases and handling time decreases monotonically as mussels become smaller, preference for smaller mussels simultaneously maximizes the net rate of energy intake and minimizes the time spent handling prey The only exception to this is the apparent equal preference shown by $C$. sapidus for all mussel sizes below about $2.5 \mathrm{~cm}$ (Table 1,2), corresponding to the range of sizes over which mussels can be easily crushed. Above this size range a different handling procedure is used, resulting in a sharp increase in handling time. Possibly, the handling time curves could be more appropriately fitted by separate functions corresponding to the different opening methods. The equal preference for all mussels in the smaller size categories suggests that time minimization may be the basis of size selection rather than energy maximization. While feeding on Geukensia demissa during high tide, $C$. sapidus may be at risk to predation by herons and egrets and to prey-robbing by conspecifics. We noticed that having opened a mussel, $C$. sapidus became far less sensitive to visual stimuli. Under these circumstances, minimizing prey handling time may be more important than maximizing the net rate of energy intake.

The recognition of suboptimal prey, whether based on profitability or expected handling time, was often reduced after a few minutes' experience, from a manipulation by the mouthparts lasting at least several seconds to an instantaneous touch by a walking leg. Such a learning capability indicates that the behavioural sophistication of Callinectes sapidus is certainly sufficient for active selection according to prey value to be feasible. The question now is how, and on what basis, does $C$. sapidus evaluate a mussel? 
Acknowledgements. The authors wish to thank the Director of Duke University Marine Laboratory, Dr J. D. Costlow, for providing research facilities. Funding through a Royal Society Travel Grant (to RNH) is also gratefully acknowledged.

\section{LITERATURE CITED}

Darnell, R. M. (1961). Trophic spectrum of an estuarine community based on studies of Lake Pontchartrain, Louisiana. Ecology 42: 553-568

Elner, R. W. (1978). The mechanics of predation by the shore crab, Carcinus maenas (L.) on the edible mussel, Mytilus edulis L. Oecologia (Berl.) 36: 333-344

Elner, R. W., Hughes, R. N. (1978). Energy maximization in the diet of the shore crab. Carcinus maenas. J. Anim. Ecol. 47: $103-116$

Hamilton, P. V (1976). Predation on Littorina irrorata (Mollusca: Gastropoda) by Callinectes sapidus (Crustacea: Portunidae). Bull. mar Sci. 26: 403-409
Hermkınd, W. F. (1968). Adaptive visually-directed orientation in Uca pugilator. Am. Zool. 8: 585--598

Hughes, R. N. (1979). Optimal diets under the energy maximization premise: the effects of recogntion tume and learn. ing. Am. Nat. 113: 209-221

Hughes, R. N. (1980). Optimal foraging theory in the marine context. Oceanogr mar. Biol. A. Rev. 18: 423-481

Hughes, R. N., Elner, R. W. (1979). Tactics of a predator, Carcinus mannas, and morphological responses of the prey, Nucella lapillus. J. Anim. Ecol. 48: 65-78

Krebs, J. R. (1978). Optimal foraging: decision rules for predators. In: Krebs, J. R., Davies, N. B. (eds.) Behavioural ecology. An evolutionary approach. Blackwell, Oxford, pp. $23-63$

Seed, R. (1980a). Predator-prey relationships between the mud crab Panopeus herbstii, the blue crab, Callinectes sapidus and the Atlantic ribbed mussel Geukensia (= Modiolus) demissa. Estuar. coast. mar Sci. 11: 445-458

Seed, R. (1980b). A note on the relationship between shell shape and life habits in Geukensia demissa and Brachidontes exustus (Mollusca: Bivalvia). J. Moll. Stud. 46: $293-299$

This paper was presented by Dr B. L. Bayne; it was accepted for printing on June 5, 1981 